Case Report

\title{
Hypothyroidism Induced Severe Rhabdomyolysis in a Hemodialysis Patient
}

\author{
Erhan Tatar, ${ }^{1}$ Tolgay Isikyakar, ${ }^{2}$ Kezban Pinar Yeniay, ${ }^{1}$ \\ Hasan Huseyin Uzuner, ${ }^{1}$ and Ebru Sevinc $\mathrm{Ok}^{1}$ \\ ${ }^{1}$ Division of Nephrology, Izmir Bozyaka Education and Research Hospital, 9035170 Izmir, Turkey \\ ${ }^{2}$ Department of Internal Medicine, Izmir Bozyaka Education and Research Hospital, 9035170 Izmir, Turkey
}

Correspondence should be addressed to Erhan Tatar; etatar@hotmail.com

Received 18 January 2014; Accepted 12 March 2014; Published 7 April 2014

Academic Editor: W. Zidek

Copyright (C) 2014 Erhan Tatar et al. This is an open access article distributed under the Creative Commons Attribution License, which permits unrestricted use, distribution, and reproduction in any medium, provided the original work is properly cited.

Hypothyroidism occurs relatively common and is a significant cause of morbidity and mortality during the course of chronic kidney disease. Rhabdomyolysis is a potentially life-threatening condition characterised by necrosis of muscular tissue and rarely associates with hypothyroidism. Here we describe a case of rhabdomyolysis due to severe hypothyroidism in a 56-year-old female hemodialysis patient.

\section{Introduction}

Thyroid dysfunction is relatively common in patients with chronic kidney disease $(\mathrm{CKD})$ when compared to general population $[1,2]$. Both hormonal changes including alterations in TRH, TSH, and iodine clearance as well as presence of associating autoimmune disorders (type 1 diabetes mellitus or systemic lupus erythematosus) and comorbidities such as HCV infection or treatment with drugs having adverse thyroid effects (e.g., amiodarone) are thought to be responsible for thyroid dysfunction [2-4]. Thyroid dysfunction particularly hypothyroidism is a significant cause of cardiovascular mortality and morbidity in CKD patients [5-10]. In hemodialysis patients, however, the frequency of acute complications and neuromuscular effects of hypothyroidism are not known.

Rhabdomyolysis is a rapid breakdown of skeletal muscle tissue leading to release of its contents into systemic circulation [11]. Rhabdomyolysis, a life-threatening condition, may occur due to physical factors including trauma, convulsions, or overexertion as well as to chemical and hormonal causes [11]. Hypothyroidism associated rhabdomyolysis is rare in nonuremic patients. Hypothyroidism induced rhabdomyolysis in dialysis patients has not been reported as far as we know. Here we present a case of rhabdomyolysis in a hemodialysis patient on amiodarone treatment receiving antithyroid therapy for subclinical hyperthyroidism.

\section{Case Presentation}

A 56-year-old female with a past medical history of end stage diabetic nephropathy, interstitial pulmonary disease, congestive heart failure, and atrial fibrillation presented to nephrology outpatient clinics with complaints of nausea and fatigue. She was back on routine hemodialysis 4 times a week for 18 months (she underwent a renal transplantation 10 years ago). She provided a history of subclinical hyperthyroidism detected six months ago for which antithyroid treatment was started because of the diagnosis of a thyroid nodule. She stated that she missed her follow-up appointments. Her medications included warfarin $5 \mathrm{mg}$, diltiazem $30 \mathrm{mg}$, amiodarone $400 \mathrm{mg}$ (started for atrial fibrillation with rapid ventricular response), propylthiouracil $300 \mathrm{mg}$, theophylline $300 \mathrm{mg}$, acetylsalicylic acid $100 \mathrm{mg}$, olanzapine $2.5 \mathrm{mg}$, citalopram $10 \mathrm{mg}$, and calcium acetate $1500 \mathrm{mg}$ daily.

On admission her blood pressure was $80 / 50 \mathrm{mmHg}$, body temperature was $36.7^{\circ} \mathrm{C}$, pulse rate was 50 beats $/ \mathrm{min}$, and respiratory rate was $12 / \mathrm{min}$. Physical examination revealed bilateral rales at the lung bases. Electrocardiogram showed atrial fibrillation with slow ventricular response with $45-50 \mathrm{bpm}$. 
TABLE 1: Thyroid function test results during hemodialysis treatment.

\begin{tabular}{|c|c|c|c|c|}
\hline & $\begin{array}{c}\text { Eighteen months prior } \\
\text { to admission }\end{array}$ & $\begin{array}{l}\text { Six months prior to admission } \\
\text { (on propylthiouracil treatment) }\end{array}$ & Upon admission & $\begin{array}{l}\text { One month after admission } \\
\text { (on levothyroxine treatment) }\end{array}$ \\
\hline $\begin{array}{l}\text { TSH (normal range) } \\
(0.41-4.25 \mathrm{uIU} / \mathrm{mL})\end{array}$ & 0.80 & $0.04 \downarrow$ & $>100 \uparrow \uparrow$ & 2.44 \\
\hline $\begin{array}{l}\text { fT3 (normal range) } \\
(2.5-3.9 \mathrm{pg} / \mathrm{mL})\end{array}$ & $2.40 \downarrow$ & $2.30 \downarrow$ & $1.5 \downarrow \downarrow$ & $2.09 \downarrow$ \\
\hline $\begin{array}{l}\text { fT4 (normal range) } \\
(0.61-1.06 \mathrm{ng} / \mathrm{dL})\end{array}$ & 1.05 & 0.98 & $0.4 \downarrow \downarrow$ & $1.53 \uparrow$ \\
\hline $\begin{array}{l}\text { Antithyroglobulin } \\
(0-100 \mathrm{IU} / \mathrm{mL})\end{array}$ & & neg & 0 (neg) & \\
\hline $\begin{array}{l}\text { Anti-TPO } \\
(0-100 \mathrm{IU} / \mathrm{mL})\end{array}$ & & neg & 0.9 (neg) & \\
\hline
\end{tabular}

Upon initial assessment laboratory studies revealed the following: hemoglobin: $10.8 \mathrm{~g} / \mathrm{dL}$, mean corpuscular volume (MCV): 78 , total leukocyte count: $13,700 / \mathrm{mm} 3$, and platelet count: $289 \times 10^{9} / \mathrm{L}$; random blood sugar: $117 \mathrm{mg} / \mathrm{dL}$, blood urea: $142 \mathrm{mg} / \mathrm{dL}$, serum creatinine: $6.61 \mathrm{mg} / \mathrm{dL}$, serum albumin: $4.06 \mathrm{~g} / \mathrm{dL}$, serum aspartate amino transferase (AST): $400(0-31) \mathrm{U} / \mathrm{L}$, serum alanine amino transferase (ALT): 71 (0-31) U/L, creatine phosphokinase (CPK): 6314 (26192) U/L, CPK-MB: 12 (2-24) U/L, troponin I: $0.252 \mathrm{ng} / \mathrm{mL}$ (0-0.06), serum lactate dehydrogenase (LDH): 3643 (135214) U/L, serum sodium: $132 \mathrm{mEq} / \mathrm{L}$, and serum potasium: $7.2 \mathrm{mEq} / \mathrm{L}$; TSH: >100 uIU, free T3: $1.5 \mathrm{pg} / \mathrm{mL}$, and free T4: 0.4 (repeated twice). Antithyroglobulin and antithyroid peroxidase antibody were negative. Basal serum cortisol level was $32.97 \mathrm{ug} / \mathrm{dL}$ (6.7-22.6). Thyroid gland size was measured to be normal on thyroid ultrasound while a heterogeneous appearance was observed including fibrous bands with no nodules. She was diagnosed with hypothyroidism induced rhabdomyolysis. Thyroid function test results during hemodialysis treatment are demonstrated in Table 1. Antithyroid and antiarrhythmic medications were discontinued. Levothyroxine replacement therapy was started with a daily dose of $100 \mathrm{mcg}$, which then gradually increased up to $200 \mathrm{mcg}$. The patient underwent daily hemodialysis during the first five days of the hospital stay. On hospital followup the patient's muscle enzymes gradually declined to normal ranges in nearly two weeks (Figure 1). The patient was discharged in good clinical condition after two weeks of hospitalization.

\section{Discussion}

Hypothyroidism related skeletal muscle involvement is observed in almost $80 \%$ of the nonuremic patient population in which muscle serum creatinine kinase is usually slightly elevated [12]. Deterioration of glycogenolysis, mitochondrial oxidative metabolism, and triglyceride turnover in thyroxine deficiency may be the responsible pathogenetic mechanisms. Hypothyroidism associated rhabdomyolysis, on the other hand, is quite rare [13]. Hypothyroidism induced rhabdomyolysis, depending on its severity, may be complicated with acute kidney injury [14]. Rhabdomyolysis tends to occur more frequently in a portion of comorbid patients

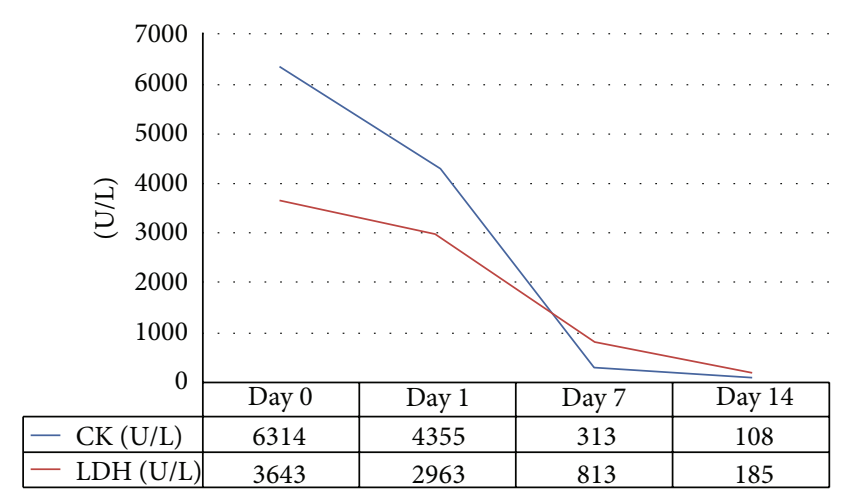

FIGURE 1: Rhabdomyolysis parameters of the patient during the hospital stay.

particularly receiving antihyperlipidemics (i.e., statins and fibrates) $[15,16]$. In the literature, however, there have been no reports regarding hypothyroidism induced rhabdomyolysis in a hemodialysis patient. Hemodialysis patients are likely to have an increased risk for hypothyroidism induced rhabdomyolysis regarding the presence of comorbidities such as electrolyte imbalances, diabetes mellitus, medications received, and drug-drug interactions (i.e., antihyperlipidemics, antihypertensives, and antiarrhythmics).

Kidneys play a significant role in thyroid hormone metabolism. Deterioration in kidney functions may lead to important alterations in thyroid functions for which a variety of mechanisms have been suggested $[3,4]$. The most common thyroid function abnormality in patients with CKD is euthyroid sick syndrome (i.e., low T3 syndrome) and hypothyroidism frequency of which increases with the severity of CKD $[1,2]$. The frequency of subclinical hyperthyroidism, on the other hand, is the same as the general population $[3,17]$. However, there is not enough information about whether to start antithyroid treatment in CKD patients with subclinical hyperthyroidism. The decision to start antithyroid treatment should be given carefully considering that thyroid function parameters in case of comorbid situations tend to vary during the course of followup, and that these medications are likely to interact with others in CKD patients, who usually are on multiple drugs. In our patient, hypothyroidism is likely 
to have developed due to antithyroid treatment started for subclinical hyperthyroidism.

Amiodarone, a class III antiarrhythmic drug, potentially interferes with normal thyroid function owing to its high iodine content $[18,19]$. It inhibits both peripheral conversion of T3 to T4 via blocking $1-5^{\prime}$ deiodinase and the entry of thyroid hormone into peripheral tissues, thereby increasing serum fT4 levels while lowering serum fT3 levels. Amiodarone alters pituitary synthesis and release of TSH and inhibits the activity of $2-5^{\prime}$ deiodinase resulting in elevated serum TSH concentrations $[18,20]$. The majority of the patients treated with amiodarone remain euthyroid whereas the treatment sometimes may lead to thyrotoxic or hypothyroid states. Amiodarone induced clinical hypothyroidism is seen in only $5 \%$ of the patients receiving the treatment. The predisposing factors are coexisting Hashimoto's thyroiditis and/or presence of autoantibodies as well as living in iodinesufficient areas [19]. Long-term amiodarone treatment is not likely to be solely responsible for the severe hypothyroidism in our patient. The antithyroid medication, kidney disease, and decreased clearance of iodine are possible contributors. Amiodarone, which is metabolized by cytochrome P450 (CYP) 3A4 in the liver, may interact with concurrent drugs (i.e., antihyperlipidemics) by interfering with their metabolism and this may lead to adverse events including rhabdomyolysis [21]. Our patient, although denied a medical history of use of antihyperlipidemic drugs, was on multidrugs, and we think that potential drug interactions could have contributed to development of rhabdomyolysis.

In conclusion, thyroid dysfunction is an important problem in hemodialysis patients. Hypothyroidism induced rhabdomyolysis may be seen, although rarely, in these patients. Hypothyroidism must be questioned in the etiological assessment of rhabdomyolysis in hemodialysis patients.

\section{Conflict of Interests}

The authors declare that there is no conflict of interests.

\section{References}

[1] J. C. Lo, G. M. Chertow, A. S. Go, and C.-Y. Hsu, "Increased prevalence of subclinical and clinical hypothyroidism in persons with chronic kidney disease," Kidney International, vol. 67, no. 3, pp. 1047-1052, 2005.

[2] M. Chonchol, G. Lippi, G. Salvagno, G. Zoppini, M. Muggeo, and G. Targher, "Prevalence of subclinical hypothyroidism in patients with chronic kidney disease," Clinical Journal of the American Society of Nephrology, vol. 3, no. 5, pp. 1296-1300, 2008.

[3] E. M. Kaptein, "Thyroid hormone metabolism and thyroid diseases in chronic renal failure," Endocrine Reviews, vol. 17, no. 1, pp. 45-63, 1996.

[4] S. Disthabanchong and A. Treeruttanawanich, "Oral sodium bicarbonate improves thyroid function in predialysis chronic kidney disease," American Journal of Nephrology, vol. 32, no. 6, pp. 549-556, 2010.
[5] C. M. Rhee, E. K. Alexander, I. Bhan, and S. M. Brunelli, "Hypothyroidism and mortality among dialysis patients," Clinical Journal of the American Society of Nephrology, vol. 8, no. 4, pp. 593-601, 2013.

[6] C. Zoccali, F. Benedetto, F. Mallamaci et al., "Low triiodothyronine and cardiomyopathy in patients with end-stage renal disease," Journal of Hypertension, vol. 24, no. 10, pp. 2039-2046, 2006.

[7] E. Tatar, F. Kircelli, G. Asci et al., "Associations of triiodothyronine levels with carotid atherosclerosis and arterial stiffness in hemodialysis patients," Clinical Journal of the American Society of Nephrology, vol. 6, no. 9, pp. 2240-2246, 2011.

[8] E. Tatar, M. S. Demirci, F. Kircelli et al., "The association between thyroid hormones and arterial stiffness in peritoneal dialysis patients," International Urology and Nephrology, vol. 44, pp. 601-606, 2012.

[9] J. J. Carrero, A. R. Qureshi, J. Axelsson et al., "Clinical and biochemical implications of low thyroid hormone levels (total and free forms) in euthyroid patients with chronic kidney disease," Journal of Internal Medicine, vol. 262, no. 6, pp. 690701, 2007.

[10] E. Tatar, F. Kircelli, and E. Ok, "The contribution of thyroid dysfunction on cardiovascular disease in patients with chronic kidney disease," Atherosclerosis, vol. 227, no. 1, pp. 26-31, 2013.

[11] F. Y. Khan, "Rhabdomyolysis: a review of the literature," Netherlands Journal of Medicine, vol. 67, no. 9, pp. 272-283, 2009.

[12] R. F. Duyff, J. van den Bosch, D. M. Laman, B.-J. Potter van Loon, and W. H. J. P. Linssen, "Neuromuscular findings in thyroid dysfunction: a prospective clinical and electrodiagnostic study," Journal of Neurology Neurosurgery and Psychiatry, vol. 68 , no. 6 , pp. $750-755,2000$.

[13] F. Monzani, N. Caraccio, G. Siciliano, L. Manca, L. Murri, and E. Ferrannini, "Clinical and biochemical features of muscle dysfunction in subclinical hypothyroidism," Journal of Clinical Endocrinology and Metabolism, vol. 82, no. 10, pp. 3315-3318, 1997.

[14] M. Altay, M. Duranay, and M. Ceri, "Rhabdomyolysis due to hypothyroidism," Nephrology Dialysis Transplantation, vol. 20, no. 4, pp. 847-848, 2005.

[15] T. J. Kiernan, M. Rochford, and J. H. McDermott, "Simvastatin induced rhabdomyolysis and an important clinical link with hypothyroidism," International Journal of Cardiology, vol. 119, no. 3, pp. 374-376, 2007.

[16] R. L. Satarasinghe, R. Ramesh, A. A. A. Riyaaz, P. A. K. G. Gunarathne, and A. P. de Silva, "Hypothyroidism is a predisposing factor for fenofibrate-induced rhabdomyolysispatient report and literature review," Drug Metabolism and Drug Interactions, vol. 22, no. 4, pp. 279-283, 2007.

[17] E. M. Kaptein, R. B. Wilcox, and J. C. Nelson, "Assessing thyroid hormone status in a patient with thyroid disease and renal failure: from theory to practice," Thyroid, vol. 14, no. 5, pp. 397400, 2004.

[18] S. Basaria and D. S. Cooper, "Amiodarone and the thyroid," American Journal of Medicine, vol. 118, no. 7, pp. 706-714, 2005.

[19] E. L. Batcher, X. C. Tang, B. N. Singh, S. N. Singh, D. J. Reda, and J. M. Hershman, "Thyroid function abnormalities during amiodarone therapy for persistent atrial fibrillation," American Journal of Medicine, vol. 120, no. 10, pp. 880-885, 2007. 
[20] J. A. Franklyn, J. R. Davis, M. D. Gammage, W. A. Littler, D. B. Ramsden, and M. C. Sheppard, "Amiodarone and thyroid hormone action," Clinical Endocrinology, vol. 22, no. 3, pp. 252264, 1985.

[21] A. Marot, J. Morelle, V. A. Chouinard, M. Jadoul, M. Lambert, and N. Demoulin, "Concomitant use of simvastatin and amiodarone resulting in severe rhabdomyolysis: a case report and review of the literature," Acta Clinica Belgica, vol. 66, no. 2, pp. 134-136, 2011. 


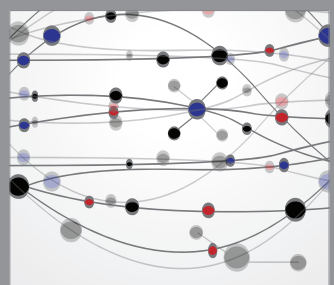

The Scientific World Journal
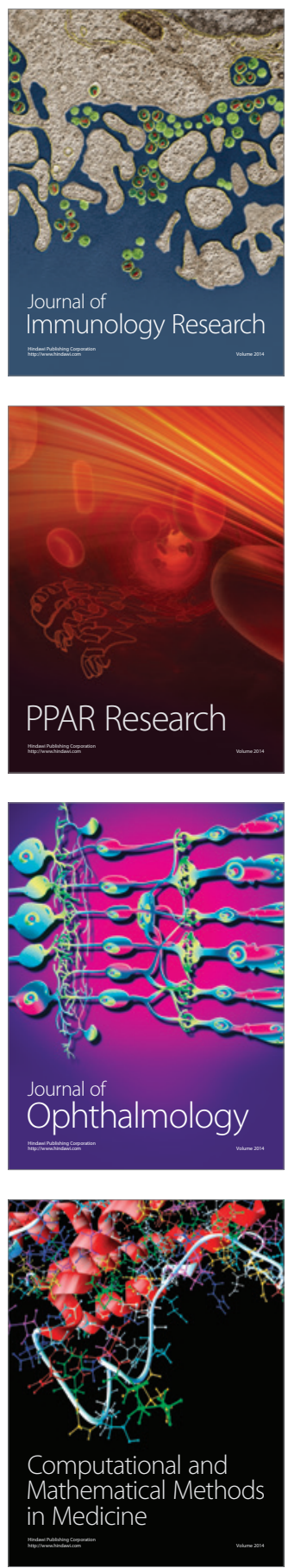

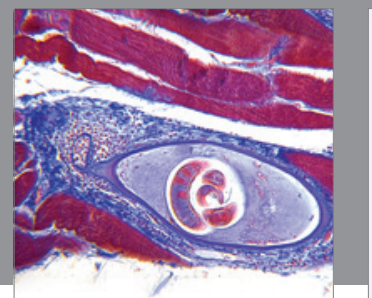

Gastroenterology

Research and Practice
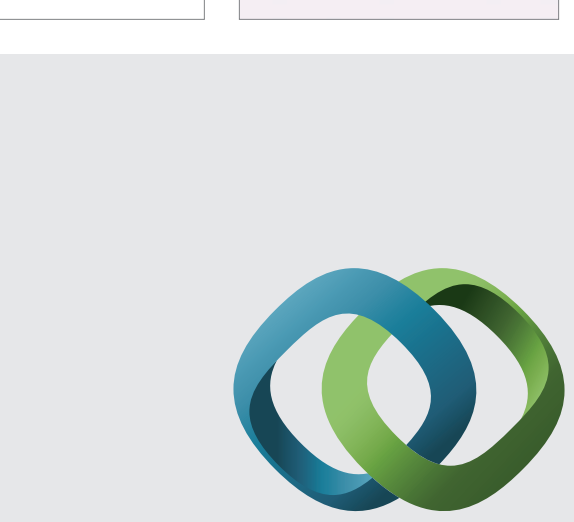

\section{Hindawi}

Submit your manuscripts at

http://www.hindawi.com
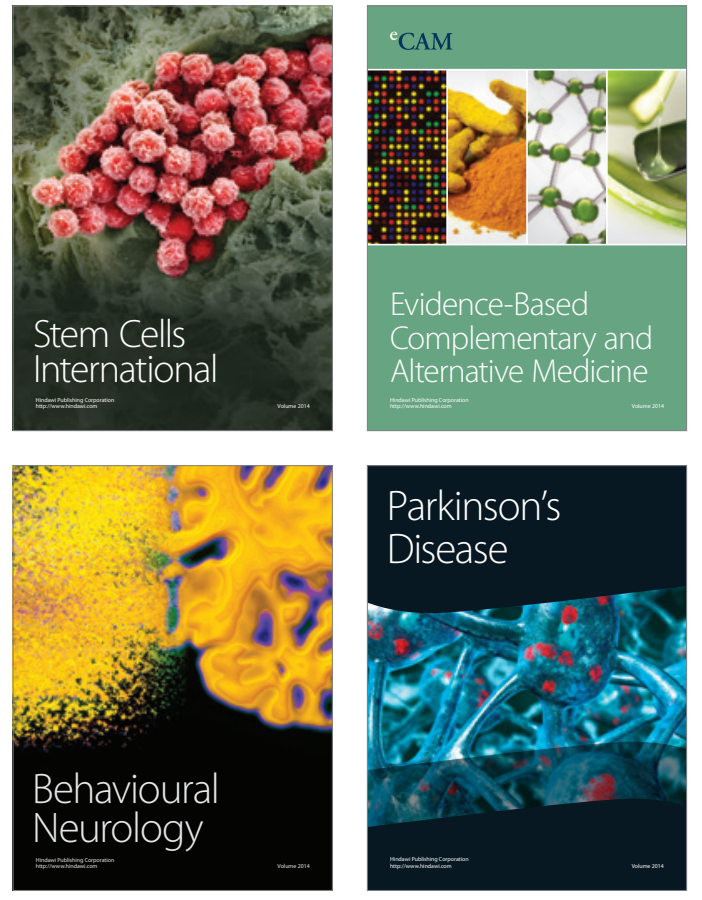
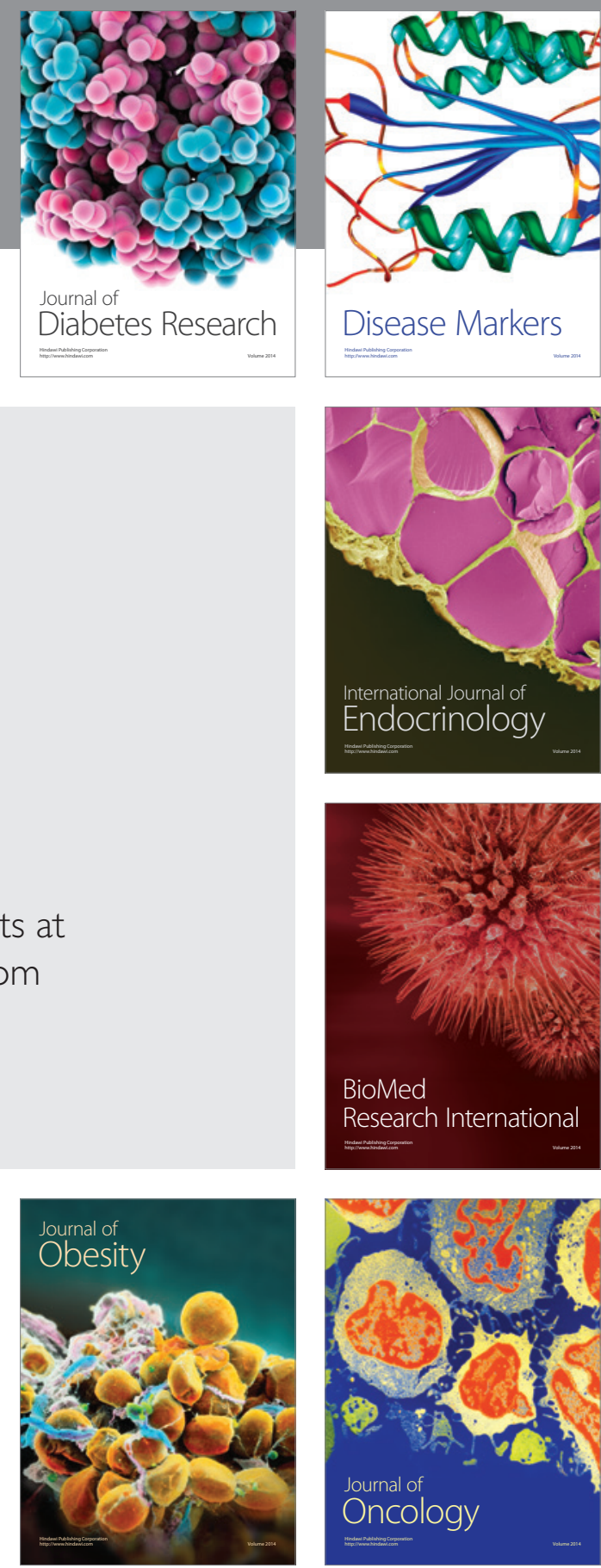

Disease Markers
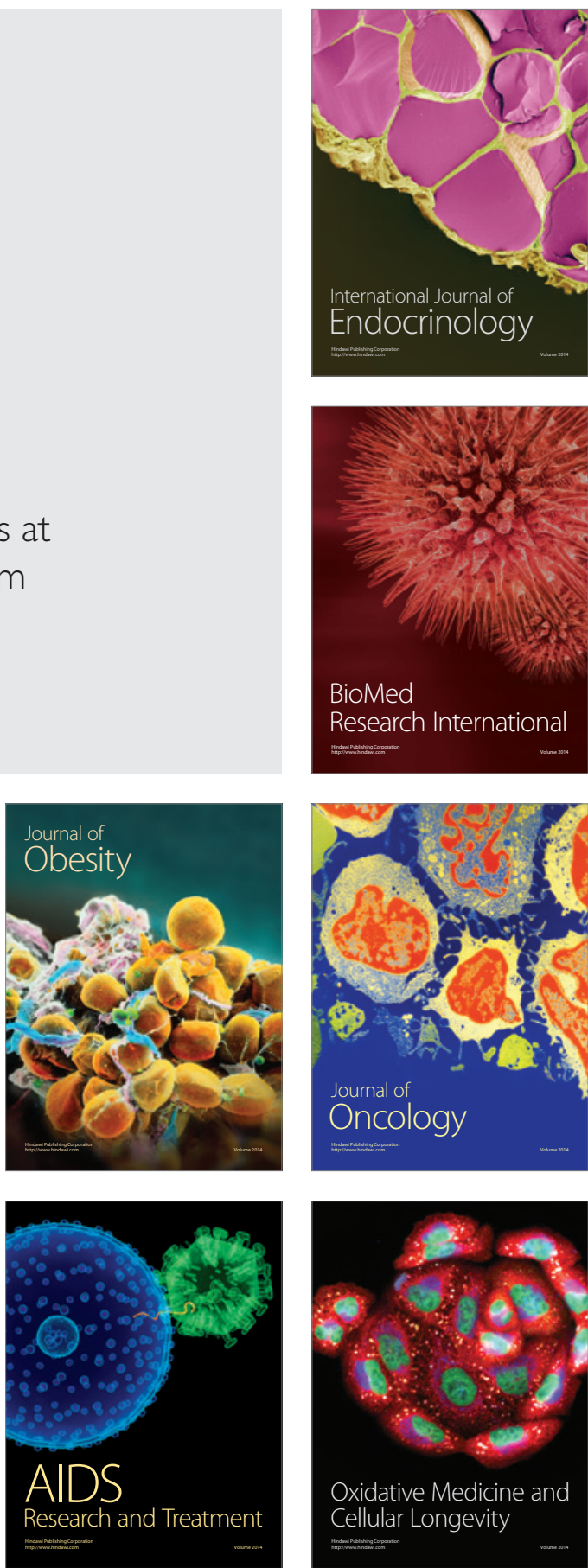